\title{
Child-directed speech: relation to socioeconomic status, knowledge of child development and child vocabulary skill
}

\section{Citation}

ROWE, MEREDITH L. 2008. "Child-Directed Speech: Relation to Socioeconomic Status, Knowledge of Child Development and Child Vocabulary Skill." Journal of Child Language 35 (01) (January 3).

\section{Published Version}

doi:10.1017/S0305000907008343

\section{Permanent link}

http://nrs.harvard.edu/urn-3:HUL.InstRepos:13041206

\section{Terms of Use}

This article was downloaded from Harvard University's DASH repository, and is made available under the terms and conditions applicable to Other Posted Material, as set forth at http:// nrs.harvard.edu/urn-3:HUL.InstRepos:dash.current.terms-of-use\#LAA

\section{Share Your Story}

The Harvard community has made this article openly available.

Please share how this access benefits you. Submit a story.

\section{Accessibility}


F. Child Lang. 35 (2008), 185-205. (C) 2008 Cambridge University Press doi:I0.1017/So305000907008343 Printed in the United Kingdom

\title{
Child-directed speech: relation to socioeconomic status, knowledge of child development and child vocabulary skill*
}

\author{
MEREDITH L. ROWE \\ University of Chicago \\ (Received 20 September 2006. Revised 2 April 2007)
}

\begin{abstract}
This study sought to determine why American parents from different socioeconomic backgrounds communicate in different ways with their children. Forty-seven parent-child dyads were videotaped engaging in naturalistic interactions in the home for ninety minutes at child age $2 ; 6$. Transcripts of these interactions provided measures of child-directed speech. Children's vocabulary comprehension skills were measured using the Peabody Picture Vocabulary Test at 2;6 and one year later at $3 ; 6$. Results indicate that: (I) child-directed speech with toddlers aged $2 ; 6$ predicts child vocabulary skill one year later, controlling for earlier toddler vocabulary skill; (2) child-directed speech relates to socioeconomic status as measured by income and education; and (3) the relation between socioeconomic status and child-directed speech is mediated by parental knowledge of child development. Potential mechanisms through which parental knowledge influences communicative behavior are discussed.
\end{abstract}

\section{NTRODUCTION}

Research documents a clear relation between socioeconomic status (SES), particularly parent education and family income, and children's vocabulary

[*] I thank Kristi Schonwald and Jason Voigt for administrative and technical support, and Karyn Brasky, Laura Chang, Elaine Croft, Kristin Duboc, Jennifer Griffin, Sarah Gripshover, Kelsey Harden, Lauren King, Carrie Meanwell, Erica Mellum, Molly Nikolas, Jana Oberholtzer, Calla Rousch, Lilia Rissman, Becky Seibel, Meredith Simone, Kevin Uttich and Julie Wallman for help in data collection and transcription. I am thankful to the participating parents for their willingness to share their knowledge and their children's language development, and to Susan Goldin-Meadow, Barbara Alexander Pan, Catherine Snow and two anonymous reviewers for commenting on earlier drafts of this paper. The research was supported by grants from the NICHD: $\mathrm{F}_{32}$ HDo45099 to the author and Por HD40605 to Susan Goldin-Meadow. Address for correspondence: Meredith L. Rowe, Department of Psychology, University of Chicago, 5848 S. University Ave, Chicago, IL 60637. e-mail: rowemer@uchicago.edu 
development. More educated and advantaged parents have children with greater vocabulary skills and faster vocabulary growth during early childhood than less educated and advantaged parents (Arriaga, Fenson, Cronan \& Pethick, I 998; Hart \& Risley, ı 995; Hoff, Laursen \& Tardif, 2002; Hoff-Ginsberg, I991; Lawrence \& Shipley, I996; Ninio, I980). Further research has shown that this relation between SES and child vocabulary skill is due, in part, to the speech that parents offer children during day-to-day interactions (Hart \& Risley, r995; Hoff, 2003a; Huttenlocher, Vasilyeva, Waterfall, Vevea \& Hedges, in press). The most compelling evidence of this sort comes from an analysis by Hoff $(2003 a)$ which shows that the mean length of utterance (MLU) and vocabulary that mothers direct to children mediates the relation between SES and child vocabulary development. High-SES mothers use longer utterances and more different words when they talk to their children than low-SES mothers and, in turn, their children have larger vocabularies (Hoff, 2003 a). The focus of the present study is to take this work one step further and address the question: WHY do more educated and advantaged parents talk more and use more complex and varied language with their children than less educated and advantaged parents?

In reviewing the literature on child-directed speech and SES it is clear that children from low-SES families experience very different communicative environments, on average, than children from high-SES families. Regarding the quantitative, or more data-providing aspects of speech (Hoff, 2003 $b$; Hoff \& Naigles, 2002), low-SES mothers are found to talk less and use less varied vocabulary during interaction with their children than high-SES mothers (Hart \& Risley, I 995; Hoff, $2003 a$; Hoff-Ginsberg, I991; Lawrence \& Shipley, I996). These differences in words spoken to children during short interactions add up to substantial cumulative differences in the communicative experiences of children during early childhood. Hart and Risley (I995) estimated that children from the highSES families they observed heard approximately i I ooo utterances in a day, compared to 700 utterances for the children from low-SES families.

Differences are apparent in the social-pragmatic aspects of speech as well. High-SES parents more often verbally encourage and provide affirmation to their children than low-SES parents, and low-SES parents more often verbally discourage and prohibit their children's behavior than high-SES parents (Hart \& Risley, I 995). Furthermore, low-SES mothers more often use speech to direct their children's behavior and high-SES mothers more often use speech to elicit conversation from their children (Farran \& Haskins, I980; Heath, I983).

There are several possible explanations for why parents from different socioeconomic backgrounds communicate in different ways with their children. One possibility is that parents from different SES groups have a 
different knowledge base or beliefs about child development which leads to different ways of communicating with children. Research on the relation between parental cognitions, beliefs and behaviors suggests that a parent's knowledge base, ‘ideas' about child development (Goodnow \& Collins, I 990), or 'beliefs' (Sigel, I 985) contributes to parenting practices, as well as to children's developmental outcomes (McGillicuddy-DeLisi \& Sigel, I 995). Recent work defines parental beliefs as knowledge based (Sigel \& McGillicuddy-DeLisi, 2002), thus the terms 'beliefs' and 'knowledge' are used interchangeably in the current study to refer to parent cognitions about children and parenting (Sigel \& McGillicuddy-DeLisi, 2002). While research supports relations between SES and parental beliefs and between parental beliefs and parenting behaviors in general (Miller, I988), few studies have investigated whether aspects of child-directed speech differ based on differences in parental beliefs about child development.

Cross-cultural research on language socialization supports a link between parents' beliefs about child development and their communication with children. For example, LeVine and colleagues show striking differences in the way middle-class mothers in the US communicate with their children compared to Gusii mothers of Kenya, with the Gusii mothers rarely making eye contact with their children and only responding to child vocalizations if the children are in distress (Richman, Miller \& LeVine, I992). The communicative actions (or non-actions) of the Gusii mothers follow from their beliefs that babies cannot understand speech and thus it is senseless to talk to them before they are older and can understand what is being said (LeVine, 2004). Similar conclusions have been drawn based on research with the Kaluli of Papua New Guinea (Ochs \& Schieffelin, I984), who believe their children to be helpless and have no understanding, and thus do not engage them in dyadic communicative interactions. Thus parents' knowledge, or 'cultural belief systems' (Harkness \& Super, I996) about child development relate to how they parent in general and, more specifically, to their communicative interactions with children.

However, the above-mentioned findings are at the population level and do not speak to the issue of SES differences in child-directed speech within Western societies. Indeed, there are studies with American samples showing a link between parental knowledge of child development and the cognitive stimulation parents provide children as measured by the Home Observation for Measurement of the Environment Inventory (Benasich \& Brooks-Gunn, I996), yet it is not clear whether the same results hold for aspects of child-directed speech. One study did find a relation between mothers' beliefs about the role the environment plays in developmental outcomes and maternal questioning strategies with children aged 4;6, suggesting that maternal beliefs about child development relate to specific aspects of communicative input (Donahue, Pearl \& Herzog, I 997). 
However, this study was homogeneous in respect to SES. Qualitative work by Heath (1983) also supports this relationship between parental beliefs and communication within low-income samples in that differences were observed in the communication African American parents offered their children compared to Caucasian parents in the same region of the southeastern United States. Differences were based on parental beliefs about children as communicative partners, with African American parents, who rarely responded to child utterances, displaying beliefs that adults cannot make babies talk and that children will 'come to know' on their own. The Caucasian parents on the other hand, often labeled objects for their children, and displayed beliefs which emphasize the important role of parents in children's development. In sum, empirical data on the relations between parental knowledge about child development and parental communication with infants and toddlers is scarce, and no research ${ }^{1}$ has systematically investigated whether or not this parental knowledge mediates the well-documented relationships between SES and child-directed speech.

A second possible explanation for the relation between SES and childdirected speech is that SES differences in child-directed speech may be due to differences in the verbal abilities of the parents. For example, several studies have shown that maternal language and literacy skills relate to the vocabulary mothers use with children (Borduin \& Henggeler, I98I; Bornstein, Haynes \& Painter, I 998; Rowe, Pan \& Ayoub, 2005). Therefore, parents who come from more educated and advantaged backgrounds may have greater language skills and more verbal facilities to draw on when interacting with their children than parents from less educated and advantaged backgrounds, and these verbal abilities may be driving the relation between SES and child-directed speech.

A third possibility is that parents from different SES groups have different styles of language use regardless of addressee. Work by Hoff (Hoff-Ginsberg, I99I; Hoff, 2003 $a, b$ ) has shown SES differences in the talk that parents address to a RESEARCHER as well as talk addressed to children. No hypothesis was offered regarding what may underlie these general styles of language use, but we do know the mothers in the Hoff study did not differ in their child-rearing beliefs or goals, as assessed by interviews with researchers.

The present study addresses the three above hypotheses by examining whether parental knowledge of child development and/or parental verbal facility are factors that might mediate, or account for, the relation between SES and child-directed speech. The third hypothesis, that parents from different SES groups have different general styles of language use regardless

[I] Yet see Bornstein, Haynes \& Painter (1998) for evidence of indirect effects. 
of addressee, is also tested, by examining relations between SES and parent's researcher-directed as well as child-directed speech.

The approach adopted here of identifying factors that mediate the relation between SES and parental behavior is guided by an ecological model of parenting (Bronfenbrenner, I 979; Luster \& Okagaki, I 993) in which multiple aspects of the parenting environment are examined to provide information about the process by which parental characteristics mediate between the larger social context and the experiences of children. Identifying factors that mediate the relation between SES and child-directed speech will provide useful information to early intervention programs targeting parent-child interaction and child language development. For example, socioeconomic status (i.e. education and income) is not very amenable to intervention, nor is parental verbal facility. However, parental knowledge of child development, if it proves an important mediator between SES and child-directed speech, can be targeted by interventions designed to enhance parent-child interaction and child language development.

First, a descriptive picture of the variation in child-directed speech within a sample of American parents is presented. Second, the relationship between child-directed speech and children's vocabulary skill is documented. Third, the relationships between SES and researcher-directed speech and child-directed speech are examined. And, finally, parental knowledge of child development and parental verbal facility are examined as mediators of the relation between SES and child-directed speech. That is, whether the relation between SES and child-directed speech is due to parental knowledge of child development and/or parental verbal facility is investigated. The specific research questions addressed are as follows:

( I) How much variation is there in the quantity and quality of childdirected speech that parents offer toddlers?

(2) Does child-directed speech with toddlers relate to children's preschool vocabulary skill, controlling for toddler vocabulary skill?

(3) Does SES relate to child-directed speech and/or researcher-directed speech?

(4) Does parental knowledge of child development and/or parental verbal facility mediate the relation between SES and child-directed speech?

METHOD

\section{Participants}

Forty-seven toddlers and their primary caregivers participated in the study. The parent-child dyads were drawn from a larger sample of 64 families participating in a longitudinal study of children's language development in the greater Chicago area. Recruitment was based on direct mailings to 
families in targeted zip codes and an advertisement in a free monthly parenting magazine. Parents who responded participated in a screening questionnaire over the phone during which information was gathered on race, ethnicity, income, education, language(s) spoken in the home, child gender and birth order. Sixty-four English-speaking families were selected to match as closely as possible the 2000 census data on family income and ethnicity in the greater Chicago area.

The criteria for drawing the sample used in the present study were the following. First, 8 of the 64 families were eliminated because in those families both parents shared the primary caregiving role and thus both parents interacted with the child in triadic interaction during data collection. These families were excluded, as the interactions were not considered comparable to the other dyadic interactions. Second, of the remaining 56 primary caregivers, 47 agreed to participate in an additional interview at child age 2;6 where detailed parent measures were collected. The 9 primary caregivers who opted not to participate did so for various reasons (e.g. 3 due to the birth of another child, 2 claimed to be too busy, and 4 were not interested or could not be reached). The final sample for the present study includes 47 primary caregiver-child dyads. One of the primary caregivers is a father and the rest are mothers. All parents speak English in the home as the primary language.

The education level of the parents was collected categorically and each category was assigned a value equivalent to years of education (less than high school degree $=$ Io years, high school degree $=\mathbf{I} 2$ years, some college or associates degree $=\mathrm{I} 4$ years, college degree $=\mathrm{I} 6$ years, more than college $=\mathrm{I} 8$ years). The primary caregivers averaged $\mathrm{i} 6$ years of education $(S D=2 \cdot 09)$ with a range from Io-1 8 years. Education levels of primary caregivers and their spouses were positively related $(r=0.52, p<0.00 \mathrm{I})$, thus only the primary caregiver's education level was used in the following analyses. Family income was also collected categorically based on predetermined ranges. For purposes of analyses, each category was assigned a dollar value equivalent to the midpoint of the category range $(\$ 7,500$; $\$ 25,000 ; \$ 42,500 ; \$ 62,500 ; \$ 87,500 ; \$ 100,000)$. The average family income was $\$ 62,889(S D=\$ 30,507)$ with a range spanning across all income categories. Thus, while SES varied widely in this sample, the distributions of both education and income were negatively skewed with more parents at the higher end of the distribution. In fact, only one parent had not received at least a high school degree and only three parents were in the lowest income bracket. Furthermore, education and income were positively related to one another $(r=0.36, p<0.05)$.

Regarding ethnicity, 34 of the parents are Caucasian, 5 are African American, 5 are Hispanic, and 3 are Asian. Nineteen of the children are girls, and 28 are first-born. Parental age ranged from ig to 45 years $(M=33.5$, 
$S D=6 \cdot 3$, and children were, on average, $2 ; 6$ during the parent-child videotaped interactions $(S D=0.30$ months). When it was not possible to conduct the parent interviews on the same day as the parent-child interactions, they were scheduled for as close to that day as possible. On average, parent interviews occurred within 5 days of the parent-child interaction $(S D=7 \cdot 3$ days).

\section{Procedure and transcription}

At child age 2;6, parent-child dyads were visited in the home and were videotaped engaging in their ordinary daily activities for 90 minutes. Parents were told to interact as they normally would. The most common types of activities included playing with toys, reading books and eating meals or snacks. After the videotaped session was concluded, the experimenter also gave the child the Peabody Picture Vocabulary Test (PPVT-III; Dunn \& Dunn, I997), a measure of vocabulary comprehension. The PPVT was administered to the children again, one year later, at $3 ; 6$.

All parent and child speech in the videotaped sessions was transcribed. The unit of transcription was the utterance, defined as any sequence of words that is preceded and followed by a pause, a change in conversational turn or a change in intonational pattern. Transcription reliability was established by having a second individual transcribe 20 percent of the videotapes with a reliability criterion of 95 percent. That is, the two transcribers had to be in agreement on 95 percent of the utterances. Reliability was based on accuracy of both utterance boundaries and word transcription. In the rare cases when there were disagreements on more than 5 percent of the utterances, the remainder of utterances were examined and a third judge was consulted to resolve all utterances under question. When the transcriber and the reliability coder agreed on the accuracy of 95 percent of the utterances, the transcriber's data was used. In transcription, we were liberal in what counted as a word. All dictionary words, as well as onomatopoeic sounds (e.g. woof-woof) and evaluative sounds (e.g. woops, $u h-o h)$, were counted as words and transcribed. Transcripts were analyzed to glean measures of child-directed speech.

In the separate parent interview, also at child age $2 ; 6$, parents were administered measures of knowledge of child development and of verbal facility described below. Parents were also audiotaped describing to the researcher what a 'typical day' is like in their home and responding to specific questions about parenting. These audiotapes were transcribed following the guidelines for speech stated above.

\section{Measures}

Child-directed speech. Transcripts were coded and analyzed for speech measures that provide information about both the data-providing and 
social-pragmatic aspects of child-directed speech. The number of words (word tokens) parents produced during the 90-minute interaction served as a measure of amount of speech. Vocabulary diversity was measured using both the number of different words produced (word types) and the diversity of a parent's vocabulary (VOCD). The VOCD measure of lexical diversity is useful in that it controls for the amount of talk produced, and thus provides a less biased estimate of lexical diversity than word types or a type-token ratio (see Malvern, Richards, Chipere \& Duran (2004) for details). Sentence complexity was measured by calculating the mean length of the parents' utterances in words. Furthermore, the proportion of parental utterances coded as eliciting or directive were calculated as more socialpragmatic measures of child-directed speech. Eliciting utterances were utterances that elicited speech from the child including yes/no and wh-questions. Directive utterances were utterances that were formed in the imperative and used to direct the child's behavior (e.g. 'put the doll in the house', 'don't touch that').

Researcher-directed speech. All parents were interviewed by the author. They were prompted by the following statement: 'tell me about a typical day in your child's life, what he/she does, your routines and activities. You can start in the morning and go through the day if you'd like.' If parents responded minimally, they were encouraged by the researcher with additional prompts such as 'and then what does he/she do?'. Following the parent narrative, parents responded to the following questions about their parenting practices: ( I) How often do you read to your child? (2) How often does your child watch television or videos? (3) Is there anything in particular you are trying to teach your child right now? (4) Do you have any specific goals or hopes for your child's future? And (5), What is your favorite and least favorite thing about being a parent? On average parents were presented with a total of seven prompts or questions from the researcher, although there was a range from five to eleven. The transcripts of the narratives and question responses were analyzed for word tokens, word types, VOCD and MLU. There was no relation between any of these measures and the number of questions/prompts by the researcher during the interview. The current study focuses on characteristics of the parental speech during the interview, not the specific information portrayed by parents.

Parental knowledge of child development. Parental knowledge of child development was measured using the Knowledge of Infant Development Inventory (KIDI; MacPhee, 2002). Parents were asked to indicate whether they agree/disagree with 39 statements about child development and I9 statements on the age that children reach certain developmental milestones. The measure includes statements regarding child development during infancy and toddlerhood which were selected to address principles of infant 
development, effective rearing techniques and health and safety issues. A variety of sources were used to derive items including textbooks, infant care and public health publications, developmental tests, and pediatricians' reports about questions they frequently receive from parents. The statements included in the KIDI focus on infants' physical, social, linguistic, perceptual and cognitive development, and include principles related to early experience, social influences, atypical development and individual differences (MacPhee, 2002). Some example statements include: (I) infants understand only words they can say; (2) you must stay in the bathroom when your child is in the tub; (3) the way a child is brought up has little effect on how smart he (she) will be; (4) a good way to teach your child not to bite is to bite back; and (5) infants of 12 months can remember toys they have watched being hidden.

In scoring, the number of questions answered and accuracy are taken into account to produce a total score. A higher score indicates more knowledge of developmental processes and infant norms as based on predetermined correct responses derived from the abovementioned sources (e.g. textbooks). Parents varied widely in total KIDI scores from $48 \cdot 3$ to $93 \cdot \mathrm{I}$, with a mean score of $79.33(S D=9 \cdot 65)$. The mean for the current sample on the 58 items is slightly lower than previous means found with samples of middle-class mothers, and higher than samples of Head Start mothers (MacPhee, 2002), as might be expected for a sample diverse in SES. KIDI scores are correlated with family income $(r=0.43$, $p<0.0 \mathrm{I})$ and education $(r=0.56, p<0.00 \mathrm{I})$ in this sample, as has been found previously in other samples also diverse in SES (MacPhee, 2002). These associations cannot be accounted for simply by the readability of the KIDI, as readability indices put the KIDI at a 7 th grade reading level (MacPhee, 2002), an education level surpassed by all parents in this study.

Parental verbal facility. In the same interview, parents were also administered the vocabulary subscale of the Wechsler Adult Intelligence Scale-Revised (WAIS-R; Wechsler, I98I), a measure of verbal facility. On this subscale parents are asked to provide definitions for 35 vocabulary words and could receive a maximum raw score of 66 points. Raw scores were then standardized based on published norms for adult age; these standardized scores averaged I I $36(S D=2 \cdot 63)$.

Child vocabulary skill. Children were given the Peabody Picture Vocabulary Test (PPVT-III; Dunn \& Dunn, I997) at child age 2;6 and 3;6. Raw scores were converted to age-appropriate standardized scores based on the published norms. This measure of receptive vocabulary was chosen as the vocabulary outcome measure of choice because the PPVT is a widely used measure of vocabulary skill and provides data independent from the parent-child interaction. 
MEREDITH L. ROWE

TAB LE I. Descriptive statistics for child-directed speech measures during a 90-minute interaction at child age 2;6 (n=47)

\begin{tabular}{lcccc}
\hline Child-directed speech & M & SD & Min & Max \\
\hline Number of word tokens & 3768 & I 936 & 696 & 7673 \\
Number of word types & 435 & $\mathrm{I} 28$ & $\mathrm{I} 72$ & $7 \mathrm{I} 4$ \\
Mean length of utterance & $4 . \mathrm{I} 6$ & 0.63 & 2.55 & $5.4 \mathrm{I}$ \\
(MLU in tokens) & & & & \\
Lexical diversity (VOCD) & 75.54 & $\mathrm{II} \cdot 67$ & 45.47 & 99.00 \\
Proportion directive utterances & 0.12 & 0.06 & 0.05 & 0.26 \\
Proportion eliciting utterances & $0.3 \mathrm{I}$ & 0.07 & 0.16 & 0.50 \\
\hline
\end{tabular}

TABLE 2. Simple estimated correlation coefficients (Pearson's r) among child-directed speech measures $(\mathrm{n}=47)$

\begin{tabular}{lccccc}
\hline & $\begin{array}{c}\text { Word } \\
\text { tokens }\end{array}$ & $\begin{array}{c}\text { Word } \\
\text { types }\end{array}$ & MLU & VOCD $\begin{array}{c}\text { Proportion } \\
\text { directive }\end{array}$ \\
\hline Word tokens & & & & & \\
Word types & $0.92^{* * * *}$ & & & & \\
MLU & $0.39^{* *}$ & $0.42^{* * *}$ & & & \\
VOCD & $0.34^{*}$ & $0.47^{* * * *}$ & $0.48^{* * * *}$ & & \\
Proportion directive & $-0.42^{* *}$ & $-0.49^{* * *}$ & $-0.24 \sim$ & $-0.3 \mathrm{I}^{*}$ & \\
Proportion eliciting & 0.06 & $0.1 \mathrm{I}$ & 0.07 & -0.03 & $-0.29^{*}$ \\
\hline
\end{tabular}

$\sim p<0.10$; $p<0.05$; ** $p<0.01$; *** $p<0.00 \mathrm{I}$.

\section{RESULTS}

\section{Variation in quantity and quality of child-directed speech}

The first goal of the study is to examine the amount of variation among parents in the child-directed speech they offer their toddlers. Descriptive statistics for child-directed speech measures are presented in Table I. Parents varied widely in the amount and diversity of talk they directed to their children at $2 ; 6$. For example, some parents produced over Io times as many words or 5 times as many different vocabulary words during a 90-minute interaction with their children than other parents. Furthermore, directive utterances in the imperative made up 12 percent of utterances, on average, while eliciting utterances made up $3 \mathrm{I}$ percent of utterances, on average. Table 2 presents associations among child-directed speech measures. Not surprisingly, parents who talked more (word tokens) also produced more word types, had higher levels of lexical diversity (VOCD) and produced longer utterances (MLU) with their toddlers.

There were no relationships between quantity, diversity or complexity of parent talk and the proportion of utterances that were eliciting. However, there were negative relationships between the proportion of utterances that were used in the imperative to direct the child's behavior and the quantity 
TABLE 3. Regression models predicting child vocabulary comprehension at $3 ; 6$, based on vocabulary comprehension and child-directed speech at 2;6 $(\mathrm{n}=45)$

\begin{tabular}{|c|c|c|}
\hline \multirow[b]{2}{*}{ Predictors at $2 ; 6$} & \multicolumn{2}{|c|}{ Vocabulary comprehension (PPVT) B (se) } \\
\hline & Model I & Model 2 \\
\hline Intercept & $\begin{array}{c}50.33^{* * * *} \\
(\text { I } 0.9 \text { I })\end{array}$ & $\begin{array}{c}64 \cdot \text { I } 2 * * * * * \\
(\text { I I } \cdot 26)\end{array}$ \\
\hline Vocabulary comprehension (PPVT) & $\begin{array}{c}0.6 \mathrm{I} * * * \\
(\mathrm{O} . \mathrm{I} \mathrm{I})\end{array}$ & $\begin{array}{c}0.46^{* * * *} \\
(0.12)\end{array}$ \\
\hline Child-directed speech composite & & $\begin{array}{r}6 \cdot 09 * * \\
(2 \cdot 19)\end{array}$ \\
\hline R-squared stat (\%) & $4 I \cdot 3$ & $50 \cdot 8$ \\
\hline
\end{tabular}

* $p<0.05 ; * *$ p $<0.01 ; * * * p<0.00 \mathrm{I}$.

and diversity of parent talk. Specifically, parents who used a larger proportion of their utterances to direct their child's behavior produced fewer word tokens, and produced less diverse vocabulary (types and VOCD) than parents who used fewer of their utterances to direct their child's behavior.

To limit the overall number of child-directed speech measures, the five related measures (e.g. tokens, types, MLU, VOCD and proportion directive) were combined into a composite measure of child-directed speech using principal components analyses. Associations among these five childdirected speech measures ranged from $r=0.24$ to $r=0.92$ (see Table 2). The first principal component weighted tokens, types, MLU and VOCD positively and the proportion of directive utterances negatively. The weights for tokens and types were slightly larger than for MLU, VOCD and proportion directive, which were of relatively equal value. This principal component accounted for approximately 57 percent of the original variance. The mean score of the composite is $\circ(S D=\mathrm{I} \cdot 0)$. For a parent to score high on the child-directed speech composite she or he would have to produce many word tokens and types, produce lexically diverse speech, produce long utterances and produce a small proportion of utterances that are directive.

\section{Relation between child-directed speech and subsequent child vocabulary skill}

The second goal of the study is to document a relation between childdirected-speech and child vocabulary skill. Children varied widely in their vocabulary comprehension skills at $3 ; 6$. Normed PPVT scores ranged from 63 to 137 with an average of $106 \cdot 7(S D=\mathrm{I} 7 \cdot 5)$, slightly above the expected average of $\mathrm{s}$ oo for the general population. Two children did not complete the PPVT at $3 ; 6$, reducing the sample size to 45 for this analysis. PPVT scores in this sample were significantly related to parent education $(r=0.5 \mathrm{I}$, $p<0.00 \mathrm{I})$ and family income $(r=0.33, p<0.05)$. Table 3 presents regression 
models showing the relation between child-directed speech to toddlers and children's preschool vocabulary skill. Model I (Table 3) shows that, as expected, children's vocabulary comprehension (PPVT) at $2 ; 6$ explains a large amount of the variance (4I percent) in their vocabulary comprehension (PPVT) at $3 ; 6$. Model 2 shows that controlling for child vocabulary comprehension at $2 ; 6$, child-directed speech at $2 ; 6$ is also a significant predictor of preschool vocabulary skill, explaining approximately an additional so percent of the variance. Thus, the quantity and quality of speech that parents use with toddlers during everyday interactions does relate to children's preschool vocabulary size, even after taking children's vocabulary size during toddlerhood into account. Neither education nor income was a significant predictor of PPVT at $3 ; 6$ after controlling for PPVT and child-directed speech at $2 ; 6$.

So far, the results concur with previous findings that child-directed speech relates to children's vocabulary skill. The third goal of the study is to explore the relation between SES and parent's researcher-directed and child-directed speech.

\section{Relation of SES to researcher-directed and child-directed speech}

Parents varied widely in the quantity and diversity of talk they addressed to the researcher. Results show a significant association between the number of word types parents produced in the two situations $(r=0.33, p<0.05)$, but there was no relation between the number of words produced (tokens), the lexical diversity of the talk (VOCD) or the length of the utterances (MLU) during child-directed and researcher-directed speech. Furthermore, there were no significant relationships between SES measures (education and income) and the speech that parents directed to the researcher (tokens, types, VOCD or MLU), indicated by either simple correlations or partial correlations controlling for the number of prompts and questions posed by the researcher.

There are significant positive relations between the child-directed speech composite and parent education $(r=0.49, p<0.00 \mathrm{I})$ and between the childdirected speech composite and family income $(r=0.44, p<0.00 \mathrm{I})$. There are no relations between education or income and the proportion of eliciting utterances produced by parents. In sum, parents from more educated and advantaged backgrounds scored higher on the child-directed speech composite and thus talked more, used a more diverse lexicon, produced longer utterances and produced a smaller proportion of utterances that are directive with their toddlers at 2;6 than parents from less educated and advantaged backgrounds. As there was no relation between SES and the proportion of eliciting utterances, that measure is not included in subsequent analyses. The final set of analyses explore whether parental 
knowledge of child development and/or verbal facility mediates this relation between SES and child-directed speech.

\section{Knowledge of child development and/or verbal facility as mediating factors}

To explore whether parental knowledge of child development and/or verbal facility mediates the relation between SES and child-directed speech, the guidelines for establishing mediation offered by Baron and Kenny ( 1986$)$ were followed. In order for a variable to mediate a relation, several conditions must be met: (I) the predictor variable(s) (SES) must relate to the outcome variable (child-directed speech); (2) the predictor variable(s) (SES) must relate to the potential mediator variable (KIDI/WAIS); (3) the mediator variable (KIDI/WAIS) must relate to the outcome variable (child-directed speech); and (4) the significant relation between the predictor variable(s) (SES) and the outcome variable (child-directed speech) must reduce to non-significance upon inclusion of the significant mediator variable (KIDI/WAIS) in the model. Here, these conditions are tested using correlation and regression analyses.

The first condition, that is, that SES relates to child-directed speech, was met, as noted above. To test the second condition, the associations between SES and knowledge of child development (KIDI) and verbal facility (WAIS) were examined. Parental education was positively related to KIDI $(r=0.56, p<0.00 \mathrm{I})$ and WAIS $(r=0.50, p<0.00 \mathrm{I})$ scores, as was family income (KIDI : $r=0.43, p<0.0 \mathrm{I}$; WAIS : $r=0.37, p<0.0 \mathrm{I}$ ). Thus, more educated and advantaged parents know more about child development, as measured by the KIDI, and have more verbal facility than less educated and advantaged parents. To satisfy the third condition, the relations between the outcome variable, child-directed speech, and the potential mediating variables, KIDI and WAIS, were examined. These relations are positive and significant (KIDI : $r=0.54, p<0.00 \mathrm{I}$; WAIS : $r=0.4 \mathrm{I}, p<$ O.OI); thus parents who know more about child development and parents who have more verbal facility talk more, use more diverse vocabulary, use longer utterances and produce fewer utterances that direct their child's behavior than parents who know less about child development and parents with less verbal facility.

To determine whether the final condition is met, a series of regression models predicting the child-directed speech composite were fit and are displayed in Table 4. Model I shows the relation between SES and childdirected speech. In this model, education and income are significant positive predictors, explaining a combined $3 I^{\cdot} 5$ percent of the variance in child-directed speech. Parental knowledge of child development was examined first as a mediating factor between SES and child-directed speech. Model 2 (Table 4) includes parental knowledge of child development 
TABLE 4. A series of regression models testing whether parental knowledge of child development (KIDI) and/or parental verbal facility (WAIS) mediates the relation between SES and child-directed speech $(\mathrm{n}=47)$

\begin{tabular}{|c|c|c|c|c|}
\hline & \multicolumn{4}{|c|}{ Child-directed speech composite B (se) } \\
\hline & Model I & Model 2 & Model 3 & Model 4 \\
\hline Intercept & $\begin{array}{c}-3.58^{* *} \\
(0.99)\end{array}$ & $\begin{array}{c}-4 \cdot 84 * * * \\
(\mathrm{I} \cdot \mathrm{I} 3)\end{array}$ & $\begin{array}{c}-3.67 * * * \\
(0.99)\end{array}$ & $\begin{array}{c}-5 \cdot 23^{* * * *} \\
(\mathrm{I} \cdot 05)\end{array}$ \\
\hline Education & $\begin{array}{l}0.18 * * \\
(0.07)\end{array}$ & $\begin{array}{l}0.1 \mathrm{I} \\
(0.07)\end{array}$ & $\begin{array}{l}0.15^{*} \\
(0.07)\end{array}$ & $\begin{array}{l}0.08 \\
(0.07)\end{array}$ \\
\hline Income & $\begin{array}{c}0.01^{*} \\
(0.004)\end{array}$ & $\begin{array}{l}0.007 \\
(0.004)\end{array}$ & $\begin{array}{l}0.009 \sim \\
(0.005)\end{array}$ & $\begin{array}{l}0.006 \\
(0.004)\end{array}$ \\
\hline $\begin{array}{l}\text { Knowledge of child development } \\
\text { (KIDI) }\end{array}$ & & $\begin{array}{l}0.03^{*} \\
(0.02)\end{array}$ & & $\begin{array}{l}0.03^{*} \\
(0.01)\end{array}$ \\
\hline Verbal facility (WAIS-R) & & & $\begin{array}{l}0.06 \\
(0.06)\end{array}$ & \\
\hline Child word types & & & & $\begin{array}{l}0.004^{* * *} \\
(0.001)\end{array}$ \\
\hline R-squared stat (\%) & $3 I \cdot 5$ & $37 \cdot 7$ & $33 \cdot 2$ & $48 \cdot 8$ \\
\hline
\end{tabular}

$\sim p<0.10 ; * p<0.05 ; * * 1<0.01 ; * * * p<0.001$.

(KIDI) as a predictor, controlling for education and income. Here, the previously significant relations between SES (education and income) and child-directed speech are no longer significant when KIDI is included in the model, and KIDI is a significant positive predictor $(p<0.05)$ of child-directed speech explaining an additional 6 percent of the variance. Thus, the final condition of mediation is met, supporting the hypothesis that parental knowledge of child development mediates the relation between SES and child-directed speech.

Next, parental verbal facility was examined as a mediating factor. Model 3 (Table 4) includes parental verbal facility (WAIS) as a predictor of child-directed speech, controlling for education and income. Here, while the parameter estimates for the effects of education and income reduce slightly from Model I, education remains a significant predictor $(p<0.05)$ and income remains marginally significant $(p<0 \cdot 10)$. Furthermore, parental verbal facility (WAIS) does not significantly relate to child-directed speech when SES is controlled. Thus, verbal facility does not mediate the relation between SES and child-directed speech.

As a final step, other important control variables were added to the model containing education, income and knowledge of child development (Model 2). First, the children's vocabulary production (word types) during the 90-minute interaction at 2;6 was included as a predictor, as the child's vocabulary skill may influence the parent's child-directed speech. Model 4 (Table 4 ) shows that controlling for child vocabulary production $(p<0 \cdot 0 \mathrm{I})$ 
during the interaction as well as parental education and income, parental knowledge of child development remains a significant predictor $(p<0.05)$ of child-directed speech. Furthermore, child vocabulary production explains an additional I I percent of the variance in child-directed speech. Other background characteristics, including parental age, parental ethnicity, child gender and child birth order, were also examined to determine if they were significant predictors of child-directed speech if added to Model 4 and none proved significant at the $p<0.05$ level.

\section{DISCUSSION}

Despite broad consensus of the relation between SES (e.g. education and income) and child-directed speech within Western societies, it is surprising that we do not have a clear understanding of what is driving this relationship. The present study provides some insight into why parents from different SES groups communicate in different ways with their children. Most notable is the current finding that parental knowledge of child development mediates the relationship between SES and child-directed speech, suggesting that parents from different SES groups have different beliefs about child development which influence how they communicate with their children on a day-to-day basis. This finding and its implications are discussed in more detail, after reviewing other relevant results regarding relations between child-directed speech, SES and child vocabulary skill.

In this study it was essential to first replicate previous findings documenting relations between child-directed speech and child vocabulary skill, and between SES and child-directed speech, before answering the crucial question concerning why parents from different SES backgrounds communicate differently with their children. Consistent with previous work, the current findings show that more talk, more diverse and complex talk, and limited use of directive utterances by parents is associated with larger vocabulary size in children (Arriaga et al., I 998; Hart \& Risley, I 995; Hoff, 2003a; Huttenlocher, Haight, Bryk, Seltzer \& Lyons, I99I; Pan, Rowe, Singer \& Snow, 2005). Taken together the child-directed speech composite in this study explained approximately ten additional percentage points of the variance in child vocabulary comprehension above and beyond children's earlier vocabulary abilities. The magnitude of the effect of childdirected speech is most likely an underestimate, as controlling for children's earlier vocabulary comprehension already controls for some of the prior effects of child-directed speech. These results complement those of Hoff $(2003 a)$ by showing that child-directed speech relates to vocabulary comprehension as well as production and add further support to the importance of the early communicative environment in language learning. 
The findings from the present study also replicate previous findings of a relation between SES and child-directed speech (Hart \& Risley, I995; Hoff, 2003a; Huttenlocher et al., in press; Rowe et al., 2005). In the current study both parent education and family income relate to the communication that parents offer children on a day-to-day basis. Specifically, more educated and advantaged parents talk more to their children, use more diverse vocabulary and longer utterances, and produce a smaller proportion of utterances that direct their child's behavior than less educated and advantaged parents. Surprisingly, there was no positive relationship in this study between SES and the proportion of parental utterances that were conversation eliciting, as has been found previously (Farran \& Haskins, I980; Heath, I983). However, the current results concur with some previous research, as Hoff-Ginsberg (I99I) also found SES differences in the number of directives mothers used with children, but not in the number of conversation-eliciting utterances produced. Perhaps the amount of parental questioning is not a sensitive enough measure to capture SES differences, and specific characteristics of the questions should be considered. For example, high-SES parents may ask more test questions (Heath, I983), or questions testing their children's knowledge as are common in a school environment, whereas low-SES parents may ask more yes/no questions or questions that require a less extensive response.

With the above relationships documented, the primary goal of the present study was to identify factors that mediate the relation between SES and child-directed speech to help understand why it is that parents from different socioeconomic backgrounds communicate in different ways with their children. Three potential explanations were examined and are discussed here in turn.

The first potential explanation was that parents from different SES groups have different styles of language use in general regardless of addressee. This explanation was not supported, as we did not find a relation between SES and the talk that parents direct to a researcher, despite finding that SES relates to child-directed speech. This lack of a relationship was surprising as it failed to replicate previous research by Hoff-Ginsberg (I99I), showing a relation between SES and researcher-directed speech. One possibility for the different findings in the two studies is that the parent interview questions posed in the current study were less open-ended than those posed by Hoff-Ginsberg (I99I), and resulted in shorter answers and less variation in researcher-directed speech measures. However, in the current study parents varied widely in their researcher-directed speech, with some parents using over 2500 words and 500 word types, and some using fewer than 400 words and 200 word types. Another difference between the two studies is that the researcher-directed speech in the present study consisted of both parental narratives about a typical day and parental 
responses to the researcher's questions. Perhaps the responses to questions are more influenced by SES, as shown in the Hoff-Ginsberg study (I99I), than are parental narratives. Overall, with only two studies on the topic to date, and with those two studies showing conflicting findings, we need additional findings before making any definitive conclusions about the SES-researcher-directed speech relation. However, if the current lack of a relationship is replicated in future work it might suggest that parents do indeed have different styles of communicating with their children than with other adults, and these styles of communicating with children may be guided by their knowledge of child development, whereas their styles of communicating with adults may be rooted in other factors or experiences.

The remaining potential explanations were that parental verbal facility and/or parental knowledge of child development might mediate the relation between SES and child-directed speech. Our analyses determined that parental verbal facility did not serve as a mediator, despite previous findings showing a relation between parents' verbal abilities and child-directed speech (Bornstein et al., I 998 ; Rowe et al., 2005). However, we did find that parental knowledge of child development mediated the relation between SES and child-directed speech. That is, differences in child-directed speech based on parental education level and income were due to differences in parental knowledge of child development.

The positive relationship between parental income and education levels and knowledge of child development has been found in previous studies using the KIDI (MacPhee, 2002), as well as a variety of other parental belief measures (see Miller ( I 988) for a review). A high score on the KIDI indicates more knowledge about developmental processes and norms during infancy and toddlerhood, and indicates that the parents' beliefs about principles related to early experience, social influences and individual differences are more in line with those that have been theorized to benefit children's development. These beliefs are likely due to increased education, a measure of SES in the current study. Indeed research confirms that middle-class parents often gain information about parenting from educational resources such as courses in child development, books, magazines and pediatricians, whereas low-SES parents rely more on friends, relatives and more informal experiences for parenting advice (Clarke-Stewart, I978). Since the KIDI itself is based on information from educational resources and experts it is not surprising that it is sensitive to these SES differences.

The relationship found here between parental beliefs about child development and aspects of parental communication with toddlers adds to the previous research on relations between parental beliefs and practices. Specifically, the results indicate that parents who hold beliefs about child development that are more in line with information offered by experts, pediatricians and textbooks, talk more, use more diverse vocabulary and 
longer utterances, and produce a smaller proportion of directive utterances during their everyday interactions with their toddlers, than parents who do not hold these beliefs. Importantly, these are aspects of child-directed speech found conducive to language learning. These findings are consistent with previous findings that parents who understand their children's abilities are best able to structure their child's environment to the cognitive level of the child (Miller \& Davis, I 992), thus providing challenging communicative experiences within the child's zone of proximal development, experiences likely to promote optimal development (Vygotsky, I978).

Following this reasoning, the current results suggest that parents with more knowledge of child development are more 'in tune' with their children's language abilities and adjust their child-directed speech accordingly. Research shows that when children are very young mothers accept burps and smiles as conversational turns worthy of response, yet as children grow and increase in language ability more sophisticated vocalizations are required. This is an indication that mothers fine-tune their language to the language level of their children (Snow, i977). Moreover, the ability of parents to adjust their child-directed speech to the level of the child is supported by findings showing that parents who believe their children understand more, use more varied vocabulary with their children (Rowe, 2000), and by findings from recent longitudinal studies showing that parents use more complex speech and more diverse vocabularies as children get older and increase in language ability (Huttenlocher et al., in press; Pan et al., 2005). Thus, the results from the current study indicate that parental beliefs about child development relates to child-directed speech in that it helps parents gauge their child's language abilities and fine-tune their language to the level of the child.

If this explanation of the relation between beliefs and practices is correct, than it would be interesting to know whether we would gain more by measuring parental knowledge of language development in particular, rather than child development in general. The current study and the study by Donahue and colleagues (i 997) both show relationships between parental beliefs about child development in general and child-directed speech. Donahue and colleagues did not ask parents about language development, but found that mothers who hold stronger beliefs about the power of the environment to affect positive developmental outcomes posed more questions with their four-year-old children during a referential communication task, even when child language skills were controlled. In the current study, efforts to separate parental responses to questions on the KIDI about language development versus development in general were inconclusive. Specifically, there was too little variation on the few items focused on language to see any relation with child-directed speech. While knowledge of child development in general and knowledge of language development in 
particular are likely related, more information on parents' beliefs about language development may provide a more specific means of interpretation for the relation between parental beliefs and child-directed speech. Johnston \& Wong (2002) developed a questionnaire on beliefs and practices concerning talk to children, yet there is no available validity or psychometric data on the measure. A valid and reliable instrument on parental beliefs about child language development and communication with children would be a very useful tool for the fields of child language development, parenting and early intervention.

This study was limited in several important ways. First, the sample was not a nationally representative sample and thus the findings are not generalizable to all American families. Furthermore, as discussed above, the KIDI measures the extent to which beliefs about child development concur with those offered by experts and textbooks in the field and thus does not value non-mainstream beliefs which may derive from various cultural or ethnic differences. Despite these limitations, it is clear that parental knowledge of child development is an important factor to consider for interventions targeting the early communicative environments of children. The results of the present study suggest that interventions focused on parental knowledge of child development have the potential to influence how parents communicate with children, and in turn children's subsequent language development, independent of the SES of the parents. This is an exciting possibility, as knowledge of child development is potentially more amenable to intervention than SES. Of course, interventions which provide advice to parents should be mindful of the goals of the parents, the sources of information parents are exposed to and to differences in ethnic and cultural backgrounds (Goodnow, 2002). Nevertheless, future interventions of this sort will provide important information about causal relationships, helping us to understand the specific mechanisms underlying relations between parental beliefs, parent-child communicative interaction and child language development.

\section{REFERENCES}

Arriaga, R. J., Fenson, L., Cronan, T. \& Pethick, S. J. (1998). Scores on the MacArthur Communicative Development Inventory of children from low- and middle-income families. Applied Psycholinguistics 19, 209-23.

Baron, R. M. \& Kenny, D. A. (I 986). The moderator-mediator variable distinction in social psychological research: Conceptual, strategic, and statistical considerations. Fournal of personality and social psychology 5I (6), I I 73-82.

Benasich, A. A. \& Brooks-Gunn, J. (I996). Maternal attitudes and knowledge of childrearing: Associations with family and child outcomes. Child Development 67, i i86-205.

Borduin, C. M. \& Henggeler, S. W. (I98I). Social class, experimental setting, and task characteristics as determinants of mother-child interaction. Developmental Psychology $\mathbf{1 7}$, 209-I 4 . 
Bornstein, M. H., Haynes, M. O. \& Painter, K. M. (1998). Sources of child vocabulary competence: A multivariate model. Fournal of Child Language 25, 367-93.

Bronfenbrenner, U. (1979). The ecology of human development. Cambridge, MA: Harvard University Press.

Clarke-Stewart, K. A. (1978). Popular primers for parents. American Psychologist 33, 359-69.

Donahue, M. L., Pearl, R. \& Herzog, A. (1 997). Mothers' referential communication with preschoolers: Effects of children's syntax and mothers' beliefs. Fournal of Applied Developmental Psychology 18, 133-47.

Dunn, L. M. \& Dunn, L. M. (1997). Peabody Picture Vocabulary Test, 3rd ed. Circle Pines, MN : American Guidance Service.

Farran, D. C. \& Haskins, R. (1980). Reciprocal influence in the social interaction of mothers and three-year-old children from different socioeconomic backgrounds. Child Development 5I, 780-91.

Goodnow, J. J. (2002). Parents' knowledge and expectations: Using what we know. In M. H. Bornstein (ed.), Handbook of parenting, 2nd ed., Vol. 3, 439-6o. Mahwah, NJ : Lawrence Erlbaum Associates.

Goodnow, J. J. \& Collins, W. A. (1990). Development according to parents: The nature, sources, and consequences of parents' ideas. Hillsdale, NJ : Lawrence Erlbaum Associates.

Harkness, S. \& Super, C. M. (eds) (1996). Parent's cultural belief systems: Their origins, expressions, and consequences. New York: The Guilford Press.

Hart, B. \& Risley, T. (1995). Meaningful differences in the everyday experience of young American children. Baltimore: Brookes.

Heath, S. B. (1983). Ways with words: Language, life and work in communities and classrooms. Cambridge, UK: Cambridge University Press.

Hoff, E. $(2003 a)$. The specificity of environmental influence: Socioeconomic status affects early vocabulary development via maternal speech. Child Development 74, г $368-78$.

Hoff, E. $(2003 b)$. Causes and consequences of SES-related differences in parent-to-child speech. In M. H. Bornstein (ed.), Socioeconomic status, parenting, and child development, I 47-6o. Mahwah, NJ : Erlbaum.

Hoff, E., Laursen, B. \& Tardif, T. (2002). Socioeconomic status and parenting. In M. H. Bornstein (ed.), Handbook of parenting, 2nd ed., 23I-52. Mahwah, NJ : Erlbaum.

Hoff, E. \& Naigles, L. (2002). How children use input in acquiring a lexicon. Child Development 73, 4I 8-33.

Hoff-Ginsberg, E. (I99I). Mother-child conversation in different social classes and communicative settings. Child Development 62, 782-96.

Huttenlocher, J., Haight, W., Bryk, A., Seltzer, M. \& Lyons, T. (I991). Early vocabulary growth: relation to language input and gender. Developmental Psychology 27, 236-48.

Huttenlocher, J., Vasilyeva, M., Waterfall, H. R., Vevea, J. L. \& Hedges, L. V. (in press). The varieties of speech to young children. Developmental Psychology.

Johnston, J. B. \& Wong, M.-Y. A. (2002). Cultural differences in beliefs and practices concerning talk to children. Fournal of Speech, Language, and Hearing Research 45, 9I6-26.

Lawrence, V. \& Shipley, E. F. (1996). Parental speech to middle and working class children from two racial groups in three settings. Applied Psycholinguistics 17, 233-56.

LeVine, R. A. (2004). Challenging expert knowledge: Findings from an African study of infant care and development. In U. P. Gielen \& J. L. Roopnarine (eds), Childhood and adolescence: Cross-cultural perspectives and applications, 149-65. Westport, CT: Praeger.

Luster, T. \& Okagaki, L. (I 993). Multiple influences on parenting: Ecological and lifecourse perspectives. In L. Okagaki (ed.), Parenting: An ecological perspective, 227-50. Hillsdale, NJ : Erlbaum.

MacPhee, D. (2002; first published 1981). Knowledge of Infant Development Inventory: Manual. Colorado: Colorado State University.

Malvern, D., Richards, B. J., Chipere, N. \& Duran, P. (2004). Lexical diversity and language development: Quantification and assessment. New York: Palgrave Macmillan. 
McGillicuddy-DeLisi, A. V. \& Sigel, I. E. (I995). Parental beliefs. In M. H. Bornstein (ed.), Handbook of parenting, Vol. 3, 333-58. Hillsdale, NJ : Lawrence Erlbaum Associates.

Miller, S. A. (1988). Parents' beliefs about children's cognitive development. Child Development 59, 259-85.

Miller, S. A. \& Davis, T. L. (r992). Beliefs about children: A comparative study of mothers, teachers, peers and self. Child Development 63, I 25 I-65.

Ninio, A. (I980). Picture-book reading in mother-infant dyads belonging to two subgroups in Israel. Child Development 5I, 587-90.

Ochs, E. \& Schieffelin, B. B. (I984). Language acquisition and socializations: Three developmental stories and their implications. In R. A. Shweder \& R. A. LeVine (eds), Culture theory: Essays on mind, self and emotion. 276-320. Cambridge, UK: Cambridge University Press.

Pan, B. A., Rowe, M. L., Singer, J. D. \& Snow, C. E. (2005). Maternal correlates of growth in toddler vocabulary production in low-income families. Child Development $\mathbf{7 6}, \mathbf{7 6} 3-82$.

Richman, A. L., Miller, P. M. \& LeVine, R. A. (I992). Cultural and educational variations in maternal responsiveness. Developmental Psychology 28, 6r4-2 I.

Rowe, M. L. (2000). Pointing and talk by low-income mothers and their I4-month-old children. First Language 20, 305-30.

Rowe, M. L., Pan, B. A. \& Ayoub, C. (2005). Predictors of variation in maternal talk to children: A longitudinal study of low-income families. Parenting: Science and Practice 5, 285-3 го.

Sigel, I. E. \& McGillicuddy-De Lisi, A. V. (2002). Parent beliefs are cognitions: The dynamic belief systems model. In M. H. Bornstein (ed.), Handbook of parenting. 2nd ed., Vol. 3, 485-508. Mahwah, NJ: Lawrence Erlbaum Associates.

Sigel, I. E. (1985). Parental belief systems: The psychological consequences for children. Hillsdale, NJ: Lawrence Erlbaum.

Snow, C. E. (I977). The development of conversation between mothers and babies. Fournal of Child Language 4, I-22.

Vygotsky, L. S. (1978). Mind in society: The development of higher psychological processes. Cambridge, MA: Harvard University Press.

Wechsler, D. (1981). Manual for Wechsler Adult Intelligence Scale-Revisited. San Antonio, TX: The Psychological Corporation. 